\title{
Predictive factors of neurologic deterioration in patients with spontaneous cerebellar hemorrhage: a retrospective analysis
}

Yu-Ni Ho ${ }^{1 \dagger}$, Shih-Yuan Hsu' ${ }^{2 \dagger}$, Yu-Tsai Lin ${ }^{3}$, Fu-Chang Cheng ${ }^{1}$, Yu-Jun Lin ${ }^{2,5}$, Nai-Wen Tsai ${ }^{4}$, Cheng-Hsien Lu ${ }^{4,5}$ and Hung-Chen Wang ${ }^{2^{*}}$ (iD

\begin{abstract}
Background: Cerebellar hemorrhage is a potentially life-threatening condition and neurologic deterioration during hospitalization could lead to severe disability and poor outcome. Finds out the factors influencing neurologic deterioration during hospitalization is essential for clinical decision-making.

Methods: One hundred fifty-five consecutive patients who suffered a first spontaneous cerebellar hemorrhage $(\mathrm{SCH})$ were evaluated in this 10-year retrospective study. This study aimed to identify potential clinical, radiological and clinical scales risk factors for neurologic deterioration during hospitalization and outcome at discharge.

Results: Neurologic deterioration during hospitalization developed in 17.4\% (27/155) of the patient cohort. Obliteration of basal cistern ( $p \leqq 0.001)$ and hydrocephalus ( $p \leqq 0.001)$ on initial brain computed tomography $(C T)$, median Glasgow Coma Scale (GCS) score at presentation ( $p \leqq 0.001)$ and median intracerebral hemorrhage (ICH) score $(P \leqq 0.001)$ on admission were significant factors associated with neurologic deterioration. Stepwise logistic regression analysis showed that patients with obliteration of basal cistern on initial brain CT scan had an odds ratio (OR) of 9.17 ( $p=0.002$; $95 \%$ confidence interval (Cl): 0.026 to 0.455 ) adjusted risk of neurologic deterioration compared with those without obliteration of basal cistern. An increase of 1 point in the ICH score on admission would increase the neurologic deterioration rate by $83.2 \%(p=0.010 ; 95 \% \mathrm{Cl}: 1.153$ to 2.912). The ROC curves showed that the AUC for ICH score on presentation was 0.719 ( $p=0.000 ; 95 \% \mathrm{Cl}: 0.613-0.826$ ) and the cutoff value was 2.5 (sensitivity $80.5 \%$ and specificity $73.7 \%$ ).

Conclusion: Patients had obliteration of basal cistern on initial brain $\mathrm{CT}$ and $\mathrm{ICH}$ score greater or equal to 3 at admission implies a greater danger of neurologic deterioration during hospitalization. Cautious clinical assessments and repeated brain images study are mandatory for those high-risk patients to prevent neurologic deterioration during hospitalization.
\end{abstract}

Keywords: Neurologic deterioration, ICH score, Spontaneous cerebellar hemorrhage, Risk factors

\footnotetext{
*Correspondence: m82whc@gmail.com

${ }^{+}$Yu-Ni Ho and Shih-Yuan Hsu contributed equally to this work.

2Departments of Neurosurgery, Kaohsiung Chang Gung Memorial Hospital,

Chang Gung University College of Medicine, 123, Ta Pei Road, Niao Sung,

Kaohsiung, Taiwan

Full list of author information is available at the end of the article
}

(c) The Author(s). 2019 Open Access This article is distributed under the terms of the Creative Commons Attribution 4.0 International License (http://creativecommons.org/licenses/by/4.0/), which permits unrestricted use, distribution, and reproduction in any medium, provided you give appropriate credit to the original author(s) and the source, provide a link to the Creative Commons license, and indicate if changes were made. The Creative Commons Public Domain Dedication waiver (http://creativecommons.org/publicdomain/zero/1.0/) applies to the data made available in this article, unless otherwise stated. 


\section{Background}

Spontaneous cerebellar hemorrhage (SCH) account for represent 5 to $13 \%$ of all cases of spontaneous intracerebral hemorrhage and about $15 \%$ of cerebellar strokes [16]. It is often due to hypertension and the reported mortality rate within 6 months can reach $50 \%$, and more than $60 \%$ of surviving patients had moderate or severe disability [6-8]. The prognostic risk factors of outcome in patients with $\mathrm{SCH}$ including hyperglycemia and platelet count at admission, a larger hematoma volumes or diameter, a lower Glasgow Coma Scale (GCS) at admission, and imaging findings that reveal the initial presence of hydrocephalus, intraventricular hemorrhage (IVH), the appearance of the fourth ventricle, or basal cistern obliteration have been reported in several studies $[2,6,8-12]$.

Because of its unique neurological location near the brainstem, neurologic deterioration usually results from brain stem compression due to the direct mass effect of the haematoma and/ or the development of hydrocephalus [13]. However, here is still uncertainty about which risk factors significantly influence neurologic deterioration during hospitalization in patients with $\mathrm{SCH}$.

This study aimed to identify potential clinical, radiological and clinical scales risk factors to predict neurologic deterioration during hospitalization and outcome at discharge in patients with $\mathrm{SCH}$.

\section{Methods}

\section{Study design}

This is a single-centre retrospective study. Medical records were retrospectively reviewed using pre-existing standardized evaluation forms as well as brain computed tomography (CT) findings for patients with $\mathrm{SCH}$ admitted to the Department of Neurology or Neurosurgery in our tertiary academic centre from January 2005 to April 2015. The study approved by the Institutional Review Board (IRB)/Ethics Committee (Institutional Review Board numbers: 104-0985B).

\section{Clinical assessment}

On admission, a detailed physical examination, the routine laboratory testing, and brain imaging were evaluated for all patients. The initial neurologic state was evaluated by the Glasgow Coma Scale (GCS). Then systolic blood pressure, diastolic blood pressure, heart rate, and body temperature were recorded immediately before brain computed tomography (CT) scanning. After CT scan, the ICH score was calculated by the all parameters [14]. The ICH score includes the following items: Glasgow Coma Scale score, age, infratentorial origin of ICH, cerebellar hemorrhage $(\mathrm{CH})$ volume, and presence of IVH. The ICH Score was the sum of individual points assigned as follows: GCS score 3 to 4 ( $=2$ points), 5 to $12(=1), 13$ to $15(=0)$; age $>=80$ years yes $(=1)$, no $(=0)$; infratentorial origin yes $(=1)$, no $(=0)$; $\mathrm{CH}$ volume $>=30$ $\mathrm{cm}(3) \quad(=1), \quad<30 \mathrm{~cm}(3) \quad(=0)$; and intraventricular hemorrhage yes $(=1)$, no $(=0)$. The maximal score is 5 and the lowest score is 0 .

Acute $\mathrm{SCH}$ was diagnosed by the clinical history and brain CT. Patients were excluded if they had: 1) nonspontaneous cerebellar hemorrhage, such as traumatic cerebellar hemorrhage; 2) $\mathrm{SCH}$ caused by a primary or secondary brain tumor, cavernomas, arteriovenous malformations or aneurysms, or hemorrhagic transformation of a cerebellar infarct; and 3) preexisting neurological conditions with various neurological deficits (such as stroke, head trauma, and hypoxic encephalopathy). From January 2005 to April 2015, a total of 186 patients with acute SCH were admitted to our hospital. This study is to evaluate neurologic deterioration during hospitalization, therefore, GCS $=3$ and no brain stem reflex on presentation was excluded. Finally, a total of 155 patients were enrolled in the studies (Fig. 1).

The $\mathrm{SCH}$ volumes were calculated the area occupied by the hyperdense hematoma with the $\mathrm{ABC} / 2$ formula in the initial brain CT. In the formula, $A$ indicated the largest diameter of hemorrhage by $\mathrm{CT}, \mathrm{B}$ indicated the largest diameter perpendicular to $\mathrm{A}$, and $\mathrm{C}$ indicated the CT slice thickness multiplied by the number of CT slices of the hemorrhage $[10,15]$.

In the study, we determined the presence of hydrocephalus retrospectively by the dilated temporal horns of the ventricle. The image feature is consistent with obstructive hydrocephalus. [13, 16, 17]. The image feature of brain stem compression was judged by basal cistern obliteration in the brain CT $[18,19]$. The fourth ventricle appearance was divided into 3 grades, according to Kirollos et al. study [1], as following: Grade 1, the 4th ventricle is in normal size and configuration, and located in the midline (if intraventricular hemorrhage is present, the cerebrospinal fluid is visible in the 4th ventricle); Grade 2, the 4th ventricle was partially compressed, distorted or shifting to the contralateral side (in cases of unilateral hematomas); Grade 3, the 4th ventricle is completely obliteration with shift distorting the brainstem anteriorly and obliteration of the prepontine space (even if partial compression of the 4th ventricle).

In the study, the neurosurgical interventions for management $\mathrm{SCH}$ were performed with three types: external ventricular drainage (EVD) only, midline suboccpital craniectomy for hematoma evacuation, and suboccpital craniotomy plus EVD.

Patients with neurologic deterioration during hospitalization was defined that patients presented the identified episodes of one or more of the following: 1) a spontaneous decrease in GCS motor scores of 2 points or more from the previous neurologic examination; 2) development of loss of pupillary reactivity 3) pupillary asymmetry greater than $1 \mathrm{~mm}$. [20]. 


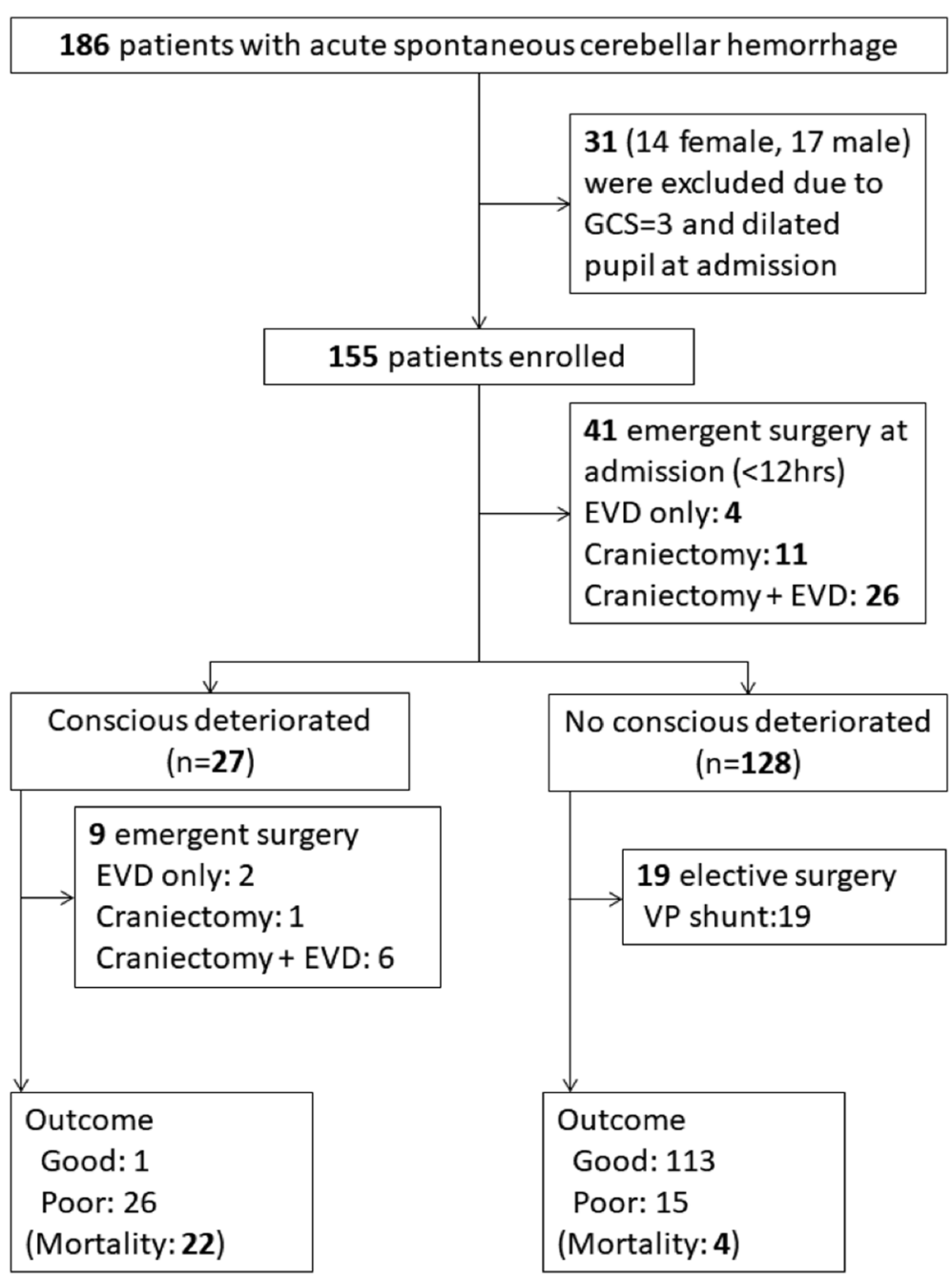

Fig. 1 Flow diagram of patients with spontaneous cerebellar hemorrhage

The patients were divided into two groups according to the discharge outcome: 1) The good outcome group with independent performance of daily activities (Glasgow Outcome scale (GOS) score $=4$ or 5). 2) The poor outcome group with disability of daily living, vegetative states, or death (GOS score $=1,2$, or 3) [10].

\section{Statistical analysis}

The descriptive data were showed as both median and inter-quartile range (IQR). Categorical variables were accessed by the Chi-square test or Fisher's exact test. The Mann-Whitney $U$ test was used for the continuous variables analysis. The Spearman rank test was applied for correlation analysis for the relationship between age, GCS and laboratory data. Statistical significance was set at $p<0.05$.

We used stepwise logistic regression analysis for evaluating the association between significant variables and patients with neurologic deterioration during hospitalization and outcome. ROC curve was generated to estimate an optimal cut-off value for ICH score on admission, and the area under ROC curve was measured. All statistical analyses were conducted using the SPSS software (IBM SPSS statistic version 22.0).

\section{Results}

From January 2005 to April 2015, a total of 186 patients with SCH were admitted to our hospital. Thirty-one patients whose GCS was 3 and without pupil reflex at presentation were excluded. A total of 155 patients finally were enrolled in this study (Fig. 1).

\section{Baseline characteristics and clinical features}

The baseline characteristics and clinical features are described in Table 1. A total of 155 patients were identified (84 males, 54.2\%). The mean age was 66 years (IQR 18 87 years). Arterial hypertension was recognized as the most common underlying disease (122 patients, $78.7 \%$ ) followed by diabetes mellitus (44 patients, $28.4 \%$ ). The 
Table 1 Characteristics of patients with spontaneous cerebellar hemorrhage

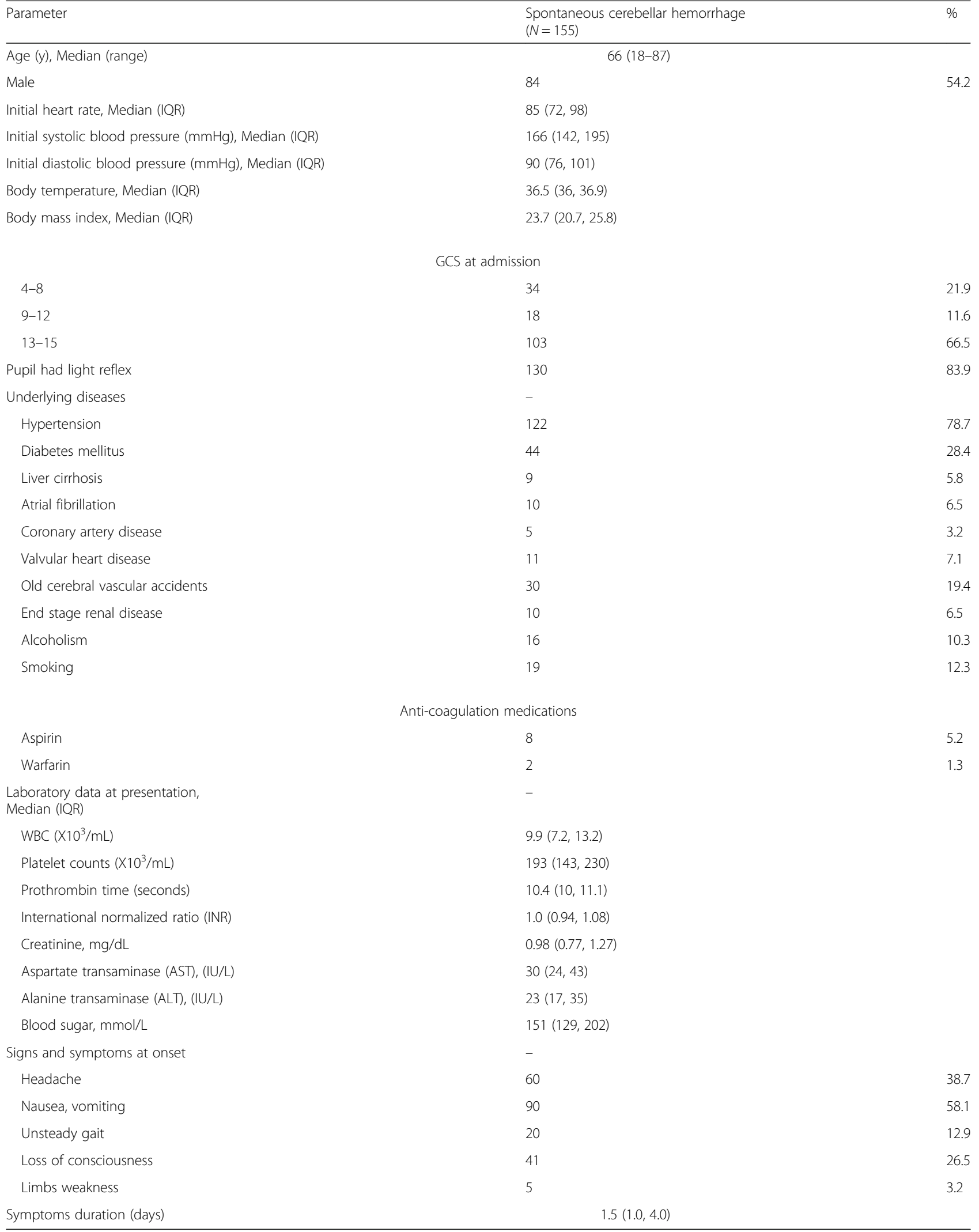


mean initial heat rate on arrive the hospital was $85 \mathrm{bpm}$ (IQR 72-98 bpm) and the mean systolic arterial blood pressure on arrival in the hospital was $166 \mathrm{mmHg}$ (IQR 142-195 mmHg). 26.5\% (41/155) patients showed loss of consciousness at initial presentation. Otherwise, signs of $\mathrm{SCH}$ and increased intracranial pressure (e.g., unsteady gaits, nausea or vomiting) were presented at 90 patients (58.1\%). The men symptoms duration was 1.5 (1.0-4.0) days.

\section{Neuroradiological findings}

Neuroradiological characteristics and neuro-surgical treatment at presentation were listed in Table 2. The median interval between hospital admission and the first brain CT was $45 \mathrm{~min}$ (IOR: 30-90 min). The median maximum hematoma dimension was $30.1 \mathrm{~mm}(\mathrm{IOR}: 20-41.1 \mathrm{~mm})$, corresponding to a median volume of $7.74 \mathrm{~cm}^{3}$ (IQR: $2.71-17.68 \mathrm{~cm}^{3}$ ) Hydrocephalus in initial image was presented in 69 patients $(44.5 \%)$. The appearance of 4th ventricle compression was grade I in $30(19.4 \%)$, grade II in $65(41.9 \%)$, and grade III in 60 (38.7\%) study sample patients. Eighty-four patients (54.2\%) exhibited obliteration of the basal cistern.

Forty-one patients (26.5\%) received neurosurgical intervention, including 11 patients (7.1\%) with suboccpital decompressive craniectomy, 4 patients $(2.6 \%)$ with EVD only, and 26 patients (16.8\%)with both suboccpital decompressive craniectomy and EVD. There were 10 patients underwent the re-operative craniectomy. The median time between symptoms and surgery was $2.46 \mathrm{~h}$ (IQR: 1.81-9.0 h). The median time of neurologic deterioration after admission was $12.5 \mathrm{~h}$ (IQR: 6-72 h).

\section{Factors predict of neurologic deterioration during hospitalization and the outcome}

Twenty-six (26/155, 16.8\%) patients died during hospitalization. Twenty-three died of the hemorrhage. Three patients died of unrelated causes, one was aspiration pneumonia, one was massive GI bleeding, and the other one was uncontrolled liver cirrhosis. Factors predict of neurologic deterioration during hospitalization and the outcome in patients with $\mathrm{SCH}$ were listed in Table 3. In total 27 patients (17.4\%) with $\mathrm{SCH}$ had neurologic deterioration during the hospitalization, 15 patients had spontaneous decrease in GCS motor score of 2 points or more from the previous examination, one had further loss of pupillary reactivity, three had development of pupillary asymmetry greater than $1 \mathrm{~mm}$, five had both spontaneous decrease in GCS motor score of 2

Table 2 Radiological characteristics at presentation and neuro-surgical treatments

\begin{tabular}{ll}
\hline Parameter & $\begin{array}{l}\text { Spontaneous cerebellar hemorrhage } \\
(N=155)\end{array}$ \\
\hline Time to first brain images (minutes), Median (IQR) & $45(30,90)$ \\
Brain images findings at presentation & - \\
Hematoma maximum dimensions (mm), Median (IQR) & $30.1(20,41.1)$ \\
Hematoma volume (mm3), Median (IQR) & $7.74(2.71,17.68)$
\end{tabular}

Hematoma location

Right hemisphere

Left hemisphere

Vermis

Involves more than two locations

Grade I

Grade ॥

Grade III

Hydrocephalus

Obliteration of basal cistern

Time to neuro-surgery (hours), Median (IQR)
69

44

20

22

Intraventricular hemorrhage grades

30

65

60

69

84

$2.46(1.81,9.0)$

Neuro-Surgical treatments
44.5

28.4

12.9

14.2

41.9

38.7

44.5

54.2

EVD only

4 
points and further loss of pupillary reactivity, and three had both spontaneous decrease in GCS motor score of 2 points and development of pupillary asymmetry greater than $1 \mathrm{~mm}$. Statistical analysis revealed significant associations of clinical feature and laboratory data at presentation are underlying disease with hypertension $(p=$ $0.038)$, liver cirrhosis $(p=0.005)$, the initial presentation with loss of consciousness $(p=0.029)$, and elevated heart rate $(p=0.010)$. Statistical analysis revealed significant associations at initial neuro-image findings are median $\mathrm{CH}$ volume ( $\mathrm{p} \leqq 0.001)$, the presentation of obliteration of basal cistern $(\mathrm{p} \leqq 0.001)$ and hydrocephalus $(\mathrm{p} \leqq 0.001)$. But there is no significant statistical difference for patients with presentation of intraventricular hemorrhage in initial $\mathrm{CT} \operatorname{scan}(P=0.108)$. GCS and $\mathrm{ICH}$ score at presentation showed significant statistical difference between the two groups (both $\mathrm{p} \leqq 0.001$ ).

The functional outcome at discharged, the neurologic deterioration group showed poor outcome compared to the no neurologic deterioration group. Only 1 of 27 patients in neurologic deterioration group had good outcome, compared to 113 of 128 patients in no neurologic deterioration group $(\mathrm{p} \leqq 0.001)$. Of these 27 patients had neurologic deterioration during hospitalization, 22 died during hospitalization. Of the five patients survived, only one had good outcome (GOS $=5$ ) with minor neurologic deficit (persistent headache, dizziness, and unsteady gait), two were vegetative state $(\mathrm{GOS}=2)$ and the other two were severe disability state $(\mathrm{GOS}=3)$ at discharged. Moreover, the $\mathrm{SCH}$ patients with neurologic deterioration during hospitalization revealed a specific high mortality rate during hospitalization. 22 of $27(81.4 \%)$ patients died during hospitalization in the neurologic deterioration group, compared to 4 of 128 (3.1\%) patients died during hospitalization in no neurologic deterioration groups $(\mathrm{P} \leqq 0.001)$.

Stepwise logistic regression analysis identified obliteran of basal cistern at initial brain $\mathrm{CT}$ and the higher $\mathrm{ICH}$ score as independent risk factors for neurologic deterioration during hospitalization. $(P=0.002$ and $P=0.010$, respectively) The adjusted risk of $\mathrm{SCH}$ patients with neurologic deterioration during hospitalization with obliteran of basal cistern at initial brain CT scan had odds ratio (OR) of 9.17 (95\% confidence interval (CI): 0.026 to 0.455 ) compared with those without obliteran of basal cistern at initial brain $\mathrm{CT}$ scan. Furthermore, an increase of 1 point in $\mathrm{ICH}$ score on admission would increase the risks of neurologic deterioration during hospitalization rate by $83.2 \%$ ( $p=0.010$; 95\% CI: 1.153 to 2.912$)$.

To determine the relationship between $\mathrm{ICH}$ score on the initial presentation and risks of neurologic deterioration during hospitalization, the ROC curves were generated. The AUC for ICH score on presentation was 0.719 ( $\mathrm{p} \leqq 0.001,95 \% \mathrm{CI}: 0.613-0.826)$. The cutoff value of ICH score on presentation was 2.5 (sensitivity $80.5 \%$ and specificity $73.7 \%$ ).

\section{Discussion}

In our study, $17.4 \%$ patients with $\mathrm{SCH}$ had neurologic deterioration during hospitalization and most of these patients $(26 / 27,96.3 \%)$ had poor outcome. Arterial hypertension, initial loss of consciousness, the presentation of obliteran of basal cistern, hydrocephalus and $\mathrm{CH}$ volume in the initial brain CT, lower GCS and higher $\mathrm{ICH}$ score are statistically significant in patients with risks of neurologic deterioration. Although those factors are statistically significant in patients with neurologic deterioration, only obliteran of basal cistern at initial brain $\mathrm{CT}$ and the higher $\mathrm{ICH}$ score as independent risk factors ( $p=0.002$ and $p=0.010$, respectively).

Several studies described the risks factors associated with neurologic deterioration in patients with spontaneous intracerebral hemorrhage. Flemming et.al [15] followed 61 patients with spontaneous supratentorial intracerebral hemorrhage and they demonstrated that the large volume lobar hematoma with consciousness disturbance $(\mathrm{GCS}<14)$ and midline shift on $\mathrm{CT}$ are at risk for further deterioration. One recent meta-analysis [21] study mentioned the risks associated with early neurologic deterioration are hematoma volume, glucose concentration, fibrinogen concentration, and d-dimer concentration at hospital admission. Those studies were focused on supratentorial intracerebral hemorrhage. Many studies showed that initial impaired consciousness is a risk factor for poor outcome in patients with acute $\mathrm{SCH}[14,22-24]$, however, there are limited studies specific focused on the risks of neurologic deterioration in patients with $\mathrm{SCH}$ or infratentorial hemorrhage.

In one previous study including 76 patients with $\mathrm{SCH}$, the preoperative GCS and IVH were not prognostic factor for the patients' outcome [13]. However, the GCS at admission was the risk factor for neurologic deterioration during hospitalization in our study. The difference between the two studies is the endpoint is different. Tsitsopoulos et.al study is to predict patient's outcome, but our study is focused on neurological deterioration during hospitalization. However, most patients had neurological deterioration during hospitalization in our study had poor outcome.

Several studies have emphasized the initial radiologic features as risk factors for patient outcomes in the cases of $\mathrm{SCH}$. The presence of hydrocephalus at admission, compression of the fourth ventricle, and obliteration of basal cisterns in neuroimages as indications for neurosurgical intervention and as prognostic factors in patients with $\mathrm{SCH}$ were mentioned in some of these studies [1, 4, 18, 19]. Indeed, the patients with neurologic deterioration during hospitalization is an another risk factor of prediction poor clinical outcome and risks 
Table 3 Neurologic deterioration during hospitalization and outcome

\begin{tabular}{|c|c|c|c|c|}
\hline & $\begin{array}{l}\text { No neurologic deteriorated } \\
N=128\end{array}$ & $\begin{array}{l}\text { Neurologic deteriorated } \\
N=27\end{array}$ & OR & $P$-Value \\
\hline (1) Age (y), Median (range) & $66.5(18-87)$ & $63(20-86)$ & & .288 \\
\hline (2) Male & 70 & 14 & 1.099 & .834 \\
\hline \multicolumn{5}{|l|}{ (3) Underlying diseases } \\
\hline Hypertension & 105 & 17 & 2.175 & .038 \\
\hline Diabetes mellitus & 37 & 7 & 1.133 & .819 \\
\hline End-stage renal failure & 6 & 4 & .397 & .073 \\
\hline Liver cirrhosis & 5 & 4 & .354 & .050 \\
\hline Atrial fibrillation & 8 & 2 & .862 & .686 \\
\hline Coronary artery disease & 5 & 0 & .820 & .588 \\
\hline Valvular heart disease & 8 & 3 & .615 & .409 \\
\hline Old cerebral vascular accidents & 22 & 4 & .806 & .568 \\
\hline Alcoholism & 12 & 4 & .662 & .483 \\
\hline Smoking & 13 & 6 & .489 & .104 \\
\hline \multicolumn{5}{|l|}{ (4) Clinical feature at presentation } \\
\hline Headache & 46 & 14 & .586 & .134 \\
\hline Nausea, vomiting & 77 & 13 & 1.491 & .287 \\
\hline Unsteady gait & 19 & 1 & 3.852 & .202 \\
\hline Loss of consciousness & 29 & 12 & .450 & .029 \\
\hline Limbs weakness & 5 & 0 & .820 & .588 \\
\hline Pupil had light reflex & 111 & 19 & 1.955 & .240 \\
\hline \multicolumn{5}{|c|}{ (5) Laboratory data at presentation, Median (IQR) } \\
\hline Heart rate, per minutes & $81(70,95)$ & $89(84,107)$ & & .010 \\
\hline Systolic blood pressure, $\mathrm{mmHg}$ & $164(142,193)$ & $170(143,219)$ & & .439 \\
\hline Diastolic blood pressure, $\mathrm{mmHg}$ & $88(77,101)$ & $90(69,101)$ & & .839 \\
\hline WBC $\left(X 10^{3} / \mathrm{mL}\right)$ & $9.6(7.2,13.1)$ & $11(7.9,13.8)$ & & .237 \\
\hline Platelet counts $\left(X 10^{3} / \mathrm{mL}\right)$ & $197(152,230)$ & $146(81,233)$ & & .070 \\
\hline Partial thromboplastin time, seconds & $10.3(10.0,11.0)$ & $10.7(9.8,12.7)$ & & .581 \\
\hline International normalized ratio & $1.0(0.95,1.07)$ & $1.02(0.91,1.24)$ & & .978 \\
\hline Blood sugar, mmol/L & $153(128,197)$ & $151(133,246)$ & & .655 \\
\hline \multicolumn{5}{|l|}{ (6) Brain Imagies Findings at presentation } \\
\hline $\mathrm{CH}$ volume (mm3) & $5.8(1.9,12.2)$ & $20.2(11.5,35.1)$ & & .000 \\
\hline Obliteration of basal cistern & 60 & 24 & .154 & .000 \\
\hline Intraventricular hemorrhage & 99 & 25 & .331 & .108 \\
\hline Hydrocephalus & 48 & 21 & .235 & .000 \\
\hline (7) Median (IQR) GCS at presentation & $15(12,15)$ & $7(5,14)$ & & .000 \\
\hline \multicolumn{5}{|l|}{ (8) Surgical intervention } \\
\hline Extraventricular drainage (EVD) & 4 & $2\left(2^{\mathrm{a}}\right)$ & & \\
\hline Suboccipital craniectomy & 6 & $6\left(1^{\mathrm{a}}\right)$ & & \\
\hline Suboccipital craniectomy + EVD & 17 & $15\left(6^{\mathrm{a}}\right)$ & & \\
\hline Ventriculo-Peritoneal Shunt & 19 & 6 & & \\
\hline (9) ICH score, Median (IQR) & $2(2,3)$ & $3(2,4)$ & & .000 \\
\hline \multicolumn{5}{|l|}{ (10) Outcome at discharged } \\
\hline Good & 113 & 1 & .014 & .000 \\
\hline Mortality & 4 & 22 & .046 & .000 \\
\hline
\end{tabular}

GCS Glasgow coma score, $O R$ odds ratio, SD standard deviation, IQR interquartile range, ICU intensive care unit,

$\mathrm{CH}$ cerebellar hemorrhage

$\left({ }^{a}\right)$ : emergent surgery while conscious deteriorated during hospitalization

Numerical variables were analyzed by Mann-Whitney U-test and Categorical variables were analyzed by chi-squared test and Fisher's exact test 
of mortality in patients with $\mathrm{SCH}$ in this study. St. Louis et al. [25] followed $72 \mathrm{SCH}$ patients and mentioned that acute hydrocephalus is the radiologic feature for predicting neurologic deterioration in patient with $\mathrm{SCH}$. Our study also demonstrated the same result. In addition, the obliteration of basal cistern seen at initial brain CT may directly compress brainstem and cause neurologic deterioration. Previous studies also showed that the impaired conscious state seen in cerebellar hemorrhage can largely be attributed to the development of hydrocephalus, resulting in intracranial hypertension and/or direct brain stem compression [13, 24]. The both image feature imply the increase of posterior fossa intracranial pressure and impairment of the CSF circulation due to the cerebellar hematoma mass effect.

The ICH score was first introduced by Hemphill et al. [26] in 2001 and was a simple and reliable scale for predicting the 30-day mortality in patients with spontaneous intracerebral hemorrhage. The ICH score includes the following items: Glasgow Coma Scale score, age, infratentorial origin of $\mathrm{ICH}, \mathrm{CH}$ volume, and presence of intraventricular hemorrhage. The maximal score is 5 and the lowest score is 0 . Therefore, the ICH score is more representative than each of the above single factors. Several studies described the role of ICH score for predicting the outcome in patients with spontaneous intracranial hemorrhage [27-29]. In our study, an increase of 1 point in ICH score on admission would increase the risks of neurologic deterioration during hospitalization rate by $83.2 \%$. ROC curve revealed the cutoff value of ICH score on presentation was 2.5 (sensitivity $80.5 \%$ and specificity $73.7 \%$ ). Base on our study, because of risks of neurologic deterioration and high possibility of poor outcome, we suggest early cautious assessments for neurosurgical intervention for those $\mathrm{SCH}$ patients whose $\mathrm{ICH}$ score are greater or equal to 3 .

In our study, the median time of neurologic deterioration after admission is $12.5 \mathrm{~h}$. Of the 27 patients had neurological deterioration during hospitalization, only one had good outcome. For those high risk patients, cautious clinical assessment and repeated neuro-image study within the first $12 \mathrm{~h}$ after admission should be considered.

There are several limitations in our study. First, it is a retrospective review. Therefore, the decision for treatment of acute $\mathrm{SCH}$, such as surgery, was individualized in each case, taking into account patient comorbidities. Second, neurologic deterioration can occur in both the acute stage and later stages during treatment. The findings may underestimate the "true" frequency of late neurologic deterioration in those patients who had been discharged. Thus, there is continued uncertainty in assessing the incidence of neurologic deterioration after $\mathrm{SCH}$ in non-selected patients. Lastly, this is a single hospital, small patient sample study.
However, after excluding secondary cerebellar hemorrhage caused by trauma, tumors, cavernomas, arteriovenous malformations or aneurysms, hemorrhagic transformation of a cerebellar infarct, patients with "pure" acute $\mathrm{SCH}$ are not easy to collect. It needs prospective, multi-center research to clarify the causes of neurologic deterioration and outcome in future.

\section{Conclusions}

In our study, $17.4 \%$ patients with $\mathrm{SCH}$ had neurologic deterioration during hospitalization and most of these patients $(26 / 27,96.3 \%)$ had poor outcome. Obliteration of basal cistern and hydrocephalus in the initial brain CT, lower GCS scale and higher ICH score on presentation implies a greater danger of neurologic deterioration during hospitalization. The median time of neurologic deterioration after admission was $12.5 \mathrm{~h}$. Cautious clinical assessment, repeated neuro-image study within the first $12 \mathrm{~h}$ after admission and possibility of early neurosurgical intervention needed to be recognized by clinical physicians for high-risk patients, especially in those with $\mathrm{ICH}$ score greater or equal to 3 , in order to early management the presence of neurologic deterioration in $\mathrm{SCH}$ patients.

\section{Abbreviations \\ CGS: Glasgow Coma Scale; CSF: Cerebrospinal fluid; CT: Computed tomography; EVD: External ventricular drainage; GOS: Glasgow Outcome scale; ICH score: Intracerebral hemorrhage score; IVH: Intraventricular hemorrhage; SCH: Spontaneous cerebellar hemorrhage}

\section{Acknowledgements \\ Not applicable. \\ Funding \\ None to report. \\ Availability of data and materials \\ The datasets used or analysed during the current study are available from the corresponding author on reasonable request.}

Authors' contributions

Conceptualization: HCW; Data collection: YNH, SYH, and FCC; Data Analysis: $L Y T, Y J L$, and NWT; Writing - original draft: YNH and SYH; Writing - review\& editing: LYT, NWT, CHL and HCW. All authors read and approved the final manuscript.

\section{Authors' information}

Not applicable.

\section{Ethics approval and consent to participate}

This study was permitted by the Institutional Review Board (IRB)/Ethics Committee of Kaohsiung Chang Gung Memorial Hospital (Institutional Review Board numbers: 104-0985B). Written informed consent was sought from all participants, in cases suffered severe disability and were not able to give informed consent, this was obtained from their legally authorized representatives as required by the IRB.

Consent for publication

Not applicable.

Competing interests

The authors have no competing of interest to declare. 


\section{Publisher's Note}

Springer Nature remains neutral with regard to jurisdictional claims in published maps and institutional affiliations.

\section{Author details}

'Departments of Emergency Medicine, Kaohsiung Chang Gung Memorial Hospital, Chang Gung University College of Medicine, Kaohsiung, Taiwan. ${ }^{2}$ Departments of Neurosurgery, Kaohsiung Chang Gung Memorial Hospital, Chang Gung University College of Medicine, 123, Ta Pei Road, Niao Sung, Kaohsiung, Taiwan. ${ }^{3}$ Departments of Otolaryngology, Kaohsiung Chang Gung Memorial Hospital, Chang Gung University College of Medicine, Kaohsiung, Taiwan. ${ }^{4}$ Departments of Neurology Kaohsiung Chang Gung Memorial Hospital, Chang Gung University College of Medicine, Kaohsiung, Taiwan. ${ }^{5}$ Department of Biological Science, National Sun Yat-Sen University, Kaohsiung, Taiwan.

\section{Received: 20 September 2018 Accepted: 18 April 2019} Published online: 01 May 2019

\section{References}

1. Kirollos RW, Tyagi AK, Ross SA, van Hille PT, Marks PV. Management of spontaneous cerebellar hematomas: a prospective treatment protocol. Neurosurgery. 2001;49(6):1378-86; discussion 86-7.

2. Hsu SY, Chang HH, Shih FY, Lin YJ, Lin WC, Cheng BC, et al. Risk factors for Ventriculoperitoneal shunt dependency in patients with spontaneous cerebellar hemorrhage. World Neurosurg. 2017:105:63-8.

3. Mathew P, Teasdale G, Bannan A, Oluoch-Olunya D. Neurosurgical management of cerebellar haematoma and infarct. J Neurol Neurosurg Psychiatry. 1995;59(3):287-92.

4. Kobayashi S, Sato A, Kageyama Y, Nakamura H, Watanabe Y, Yamaura A. Treatment of hypertensive cerebellar hemorrhage--surgical or conservative management? Neurosurgery. 1994;34(2):246-50 discussion 50-1.

5. Lui TN, Fairholm DJ, Shu TF, Chang CN, Lee ST, Chen HR. Surgical treatment of spontaneous cerebellar hemorrhage. Surg Neurol. 1985;23(6):555-8.

6. Chang CY, Lin CY, Chen LC, Sun CH, Li TY, Tsai TH, et al. The predictor of mortality within six-months in patients with spontaneous cerebellar hemorrhage: a retrospective study. PLoS One. 2015:10(7):e0132975.

7. Datar S, Rabinstein AA. Cerebellar hemorrhage. Neurol Clin. 2014;32(4):993-1007.

8. Al Safatli D, Guenther A, McLean AL, Waschke A, Kalff R, Ewald C. Prediction of 30-day mortality in spontaneous cerebellar hemorrhage. Surg Neurol Int. 2017;8:282.

9. Tao C, Hu X, Wang J, You C. Effect of admission hyperglycemia on 6-month functional outcome in patients with spontaneous cerebellar hemorrhage. Med Sci Monit. 2017;23:1200-7.

10. Lin CY, Chang CY, Sun CH, Li TY, Chen LC, Chang ST, et al. Platelet count and early outcome in patients with spontaneous cerebellar hemorrhage: a retrospective study. PLoS One. 2015;10(3):e0119109.

11. van Loon J, Van Calenbergh F, Goffin J, Plets C. Controversies in the management of spontaneous cerebellar haemorrhage. A consecutive series of 49 cases and review of the literature. Acta Neurochir. 1993;122(3-4):187-93.

12. Witsch J, Neugebauer $H$, Zweckberger $K$, Juttler E. Primary cerebellar haemorrhage: complications, treatment and outcome. Clin Neurol Neurosurg. 2013;115(7):863-9.

13. Tsitsopoulos PP, Tobieson L, Enblad P, Marklund N. Prognostic factors and long-term outcome following surgical treatment of 76 patients with spontaneous cerebellar haematoma. Acta Neurochir. 2012;154(7):1189-95.

14. Doukas A, Maslehaty $\mathrm{H}$, Barth $\mathrm{H}$, Hedderich J, Petridis AK, Mehdorn HM A novel simple measure correlates to the outcome in 57 patients with intracerebellar hematomas. Results of a retrospective analysis. Surg Neurol Int. 2015;6:176

15. Flemming KD, Wijdicks EF, St Louis EK, Li H. Predicting deterioration in patients with lobar haemorrhages. J Neurol Neurosurg Psychiatry. 1999; 66(5):600-5

16. Greenberg J, Skubick D, Shenkin H. Acute hydrocephalus in cerebellar infarct and hemorrhage. Neurology. 1979;29(3):409-13.

17. Wang YM, Lin YJ, Chuang MJ, Lee TH, Tsai NW, Cheng BC, et al. Predictors and outcomes of shunt-dependent hydrocephalus in patients with aneurysmal sub-arachnoid hemorrhage. BMC Surg. 2012;12:12.

18. Mezzadri JJ, Otero JM, Ottino CA. Management of 50 spontaneous cerebellar haemorrhages. Importance of obstructive hydrocephalus. Acta Neurochir. 1993;122(1-2):39-44.
19. Taneda M, Hayakawa T, Mogami H. Primary cerebellar hemorrhage. Quadrigeminal cistern obliteration on CT scans as a predictor of outcome. $J$ Neurosurg. 1987;67(4):545-52.

20. Juul N, Morris GF, Marshall SB, Marshall LF. Intracranial hypertension and cerebral perfusion pressure: influence on neurological deterioration and outcome in severe head injury. The executive Committee of the International Selfotel Trial. J Neurosurg. 2000;92(1):1-6.

21. Specogna AV, Turin TC, Patten SB, Hill MD. Factors associated with early deterioration after spontaneous intracerebral hemorrhage: a systematic review and meta-analysis. PLoS One. 2014;9(5):e96743.

22. Dammann P, Asgari S, Bassiouni H, Gasser T, Panagiotopoulos V, Gizewski ER, et al. Spontaneous cerebellar hemorrhage--experience with 57 surgically treated patients and review of the literature. Neurosurg Rev. 2011;34(1):77-86.

23. Han J, Lee HK, Cho TG, Moon JG, Kim CH. Management and outcome of spontaneous cerebellar hemorrhage. J Cerebrovasc Endovasc Neurosurg. 2015;17(3):185-93.

24. Pong V, Chan KH, Chong BH, Lui WM, Leung GK, Tse HF, et al. Long-term outcome and prognostic factors after spontaneous cerebellar hemorrhage. Cerebellum. 2012;11(4):939-45.

25. St Louis EK, Wijdicks EF, Li H. Predicting neurologic deterioration in patients with cerebellar hematomas. Neurology. 1998;51(5):1364-9.

26. Hemphill JC 3rd, Bonovich DC, Besmertis L, Manley GT, Johnston SC. The ICH score: a simple, reliable grading scale for intracerebral hemorrhage. Stroke. 2001;32(4):891-7.

27. Appelboom G, Hwang BY, Bruce SS, Piazza MA, Kellner CP, Meyers PM, et al. Predicting outcome after arteriovenous malformation-associated intracerebral hemorrhage with the original ICH score. World Neurosurg. 2012;78(6):646-50.

28. Hemphill JC, 3rd, Farrant M, Neill TA, Jr. Prospective validation of the ICH score for 12-month functional outcome. Neurology. 2009;73(14):1088-1094.

29. Ji R, Shen H, Pan $Y$, Wang P, Liu G, Wang $Y$, et al. A novel risk score to predict 1-year functional outcome after intracerebral hemorrhage and comparison with existing scores. Crit Care. 2013:17(6):R275.

Ready to submit your research? Choose BMC and benefit from:

- fast, convenient online submission

- thorough peer review by experienced researchers in your field

- rapid publication on acceptance

- support for research data, including large and complex data types

- gold Open Access which fosters wider collaboration and increased citations

- maximum visibility for your research: over $100 \mathrm{M}$ website views per year

At $\mathrm{BMC}$, research is always in progress.

Learn more biomedcentral.com/submission 